1 COSTS ESTIMATION OF AN INTEGRATED PROCESS FOR THE

2 TREATMENT OF HEAVY-METAL LOADED AQUEOUS

\title{
3 EFFLUENTS
}

4 Llanos J., Camarillo R., Pérez A., Cañizares P., Rodrigo M. A.*

5

6 Chemical Engineering Department, Faculty of Chemical Sciences, University of

7 Castilla-La Mancha. Edificio Enrique Costa Novella, Avda. Camilo José Cela 12, 13071

8 Ciudad Real, Spain.

9

10 *Corresponding author. Tel.: +34-926-29-53-00 Ext. 3411; fax: +34-926-29-52-56

11 E-mail: manuel.rodrigo@uclm.es

12

13

14

15

16

17

18

19

20

21

22 


\section{$1 \quad$ Abstract}

2 This work aims at providing a guide for the calculation of investment and operation

3 costs of a process to treat diluted streams of heavy metal ions. This process is composed

4 of two stages: 1) a metal concentration stage by Polymer Supported Ultrafiltration; 2) a

5 polymer regeneration and metal recovery by electrodeposition. First of all, the most

6 relevant parameters to be used in the process design will be correlated with the key

7 working variables. Next, these parameters will be related with the cost of the main

8 investment of the plant, providing Williams equations based on both literature and

9 suppliers' budgets. Finally, a detailed costs calculation for the most representative

10 values of the working variables will be presented as example.

11

12

13

14 Keywords:

15 Water treatment, cost, Williams equation, metal ions, ultrafiltration, electrodeposition. 


\section{Introduction}

2

3 produce water effluents loaded with heavy metal ions. As a consequence, the

4 development of techniques to face the treatment of these effluents is a compulsory step

5 to be taken into account in these industrial processes. Moreover, this treatment can also

6 be an economical opportunity as the reuse of concentrated streams of these metal ions in

7 the process, as well as the recovery of these metals in its metallic form, can give an

8 economic return to the main process. unavoidable step to check the viability of the process. Nevertheless, it is not easy to find

11 in the existing literature simple cases of economical assessments applied to actual 12 engineering applications, mainly those focussed on providing figures and equations to 13 be directly used to tackle the costs calculation for a given scenario. More specifically, 14 the previous works regarding economical assessments in the field of water treatment and reuse [1-4] are not conceived to be a guide of the costs calculation process, but they are focussed just on demonstrating if the target process is or not economically viable. treatment cost of an aqueous effluent loaded with heavy metal ions. The target effluents may be diluted streams $\left(<0.5 \mathrm{~g} \mathrm{~L}^{-1}\right)$ but with a heavy metal concentration clearly above its allowable disposition limit.

The main aim of the process is the production of a treated effluent with a metal concentration below its discharge limit, as well as the recovery of the heavy metal. The proposed treatment plant would be part of a more complex industrial process (v. g.: 
1 disposal of the treated effluent and avoiding the costs of its treatment by an authorized

2 waste management company. At this point, it is worth mentioning that this study could

3 be extrapolated to similar effluents loaded with metal ions different from $\mathrm{Cu}^{2+}$.

4

5

6

7

8

The first step should be the selection of a suitable technology. According to previous research work [5-7], the proposed process is based on the technique of Polymer Supported Ultrafiltration (PSU), using partially ethoxylated polyethylenimine (PEPEI) as water-soluble polymer, and electrodeposition.

Polymer Supported Ultrafiltration (PSU) is based on the addition of a watersoluble polymer, which has the ability to bind heavy metal ions, to the effluent to be treated. After this step, the target metal ion gets macromolecular size so it can be retained by an ultrafiltration membrane. Thus, the effluent is treated by performing an ultrafiltration stage, in which the retentate stream is enriched in the heavy metal ion, being separated from the rest of micro-solutes, which pass through the membrane and become part of the permeate stream [8-12].

This kind of processes is based on two consecutive steps. First of all, the effluent is concentrated in target metal ion by using the PSU technique. Next, it is necessary to regenerate the polymer and recover the metal ion, in order to guarantee the technical, environmental and economical viability of the process [9]. Although some chemical regeneration methods have been previously applied [13], one of the best regeneration techniques in terms of operability and economics is the electrochemical one [6]. This method is based on the metal electro-deposition upon the cathode of an electrochemical cell, meanwhile polymer remains in solution and can be re-cycled $[14,15]$. The technical viability of this technique for the $\mathrm{Cu}^{2+}$-PEPEI pair has been proved in previous works, but its economical viability has not been checked yet. 
In the present work, the required value of the two key parameters of the system

2 (membrane area for ultrafiltration stage, and electrode area for electrodeposition) will be

3 obtained as a function of the most important variables of the system. Next, two

4 Williams equations will be proposed in order to obtain the cost of the main equipment

5 of the system as a function of these key parameters. Finally, the total investment and

6 operation costs will be calculated for typical working conditions and the influence of

7 current density on the total treatment costs will be also evaluated.

\section{2. Electrochemical recovery of $\mathrm{Cu}^{2+}$ effluents from a PSU Process}

Figure 1 shows a typical PSU process (part a), capable of concentrating copper

10 wastes, coupled with an electrodeposition stage to recover the metal ion and regenerate

11 the polymer (part b).

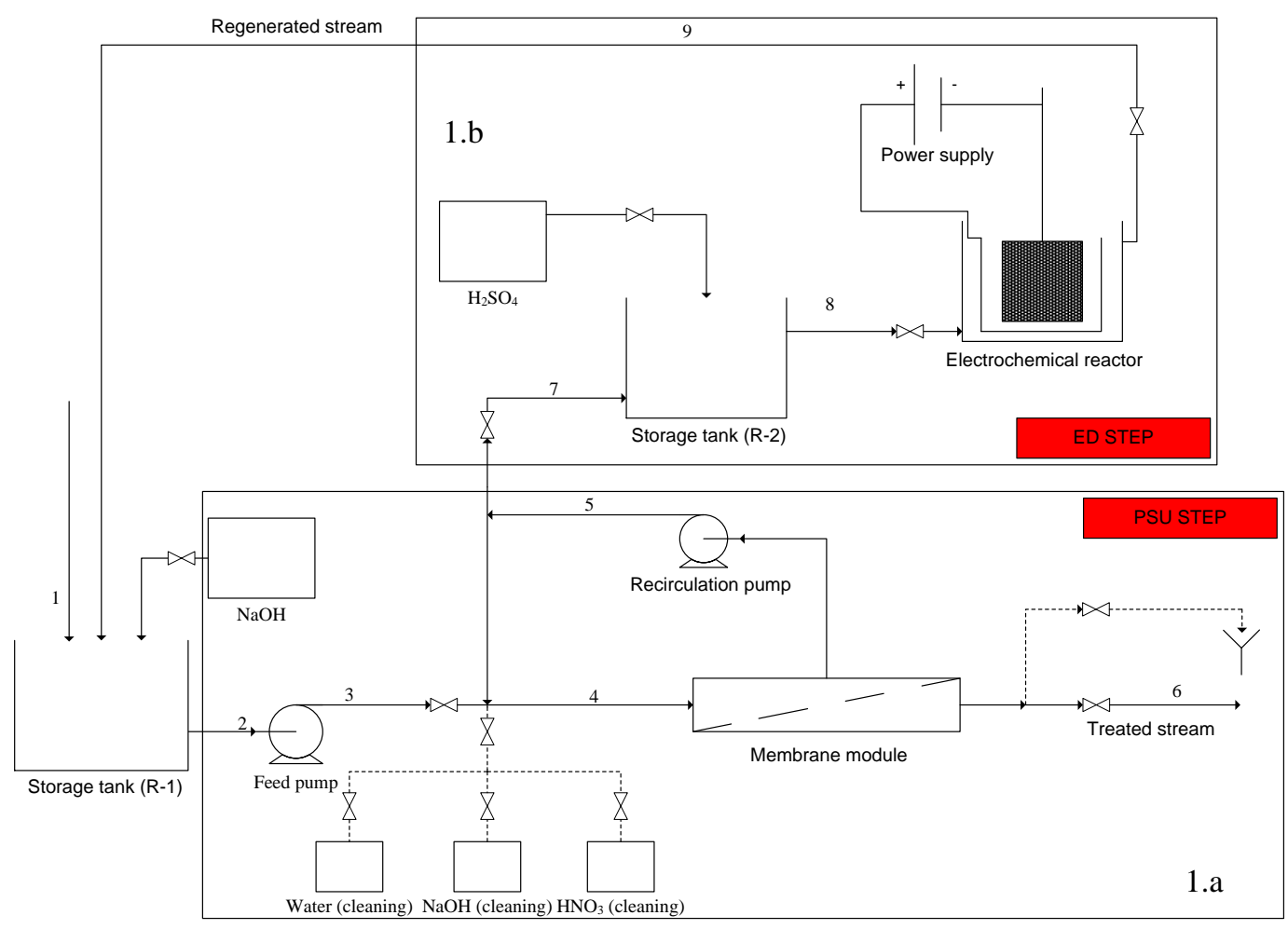

Fig. 1. Schematic plot of the continuous process of heavy metal ions recovery. 1.a) PSU stage; 1.b) 
2 also obtaining a final stream almost free of metal ion (stream 6). The most important

3 equipments that are involved in the concentration stage of this process are: 1) a storage

4 tank at the process intake, $\mathrm{R}-1 ; 2$ ) a feed pump, which increases the intake pressure to

5 the required value in the ultrafiltration module; 3) a recirculation pump, which rises

6 tangential velocity of the module inlet until the design value required at the

$7 \quad$ ultrafiltration module; and 4) ultrafiltration modules.

8 Although many membrane technologies can be used to concentrate metal-

9 containing wastes, PSU process is one of the most innovative technologies because it

10 possesses some advantages with respect to other membrane techniques of lower

11 selectivity and permeate flux as reverse osmosis or nanofiltration (v. g. higher

12 selectivity and higher permeate flux).

13 With respect to the design of this first stage, it will be considered that

14 ultrafiltration stage is carried out at continuous mode as it is the most economical mode

15 of operation for treatment rates higher than $5 \mathrm{~m}^{3}$ day $^{-1}$. Furthermore, it will be

16 considered that from every 8 hours of working shift, 6 hours will be spent on the

17 retention stage and 2 on the cleaning process.

18 Design specifications selection should be carried out based on tests at both

19 laboratory and pilot scales, working with experimental set-ups the results of which can

20 be extrapolated to the industrial plant. In the case of ultrafiltration stage, these variables

21 should be selected on the basis of the evolution of permeate flux and rejection

22 coefficients. For the former, it is important to work outside the zone of mass transfer

23 control, whereas for the latter it is compulsory to assure polymer and metal rejection

24 coefficients high enough to guarantee a good quality of the final effluent. In the case of

25 PSU processes, $\mathrm{pH}$ values slightly acidic but close to neutrality are usually selected as 
1 both permeate fluxes and rejection coefficients reach their maximum in this zone [16].

2 With regard to transmembrane pressure, permeate flux is not hardly affected by mass

3 transfer limitations if low polymer concentrations are used and if pressures from 0 to 4

4 bar are applied [7].

Once $\mathrm{pH}$ and transmembrane pressure are selected, the first parameter to be

6 fixed is the polymer/metal loading ratio (LR) that should be used to assure a high

7 rejection coefficient of the target metal ion. For this purpose, it is possible to carry out

8 different experiments with increasing polymer/metal loading ratios and fix a rejection

9 threshold that assures a good quality of the target effluent. Fig. 2 shows the evolution of

10 copper rejection coefficients with LR at different transmembrane pressures.

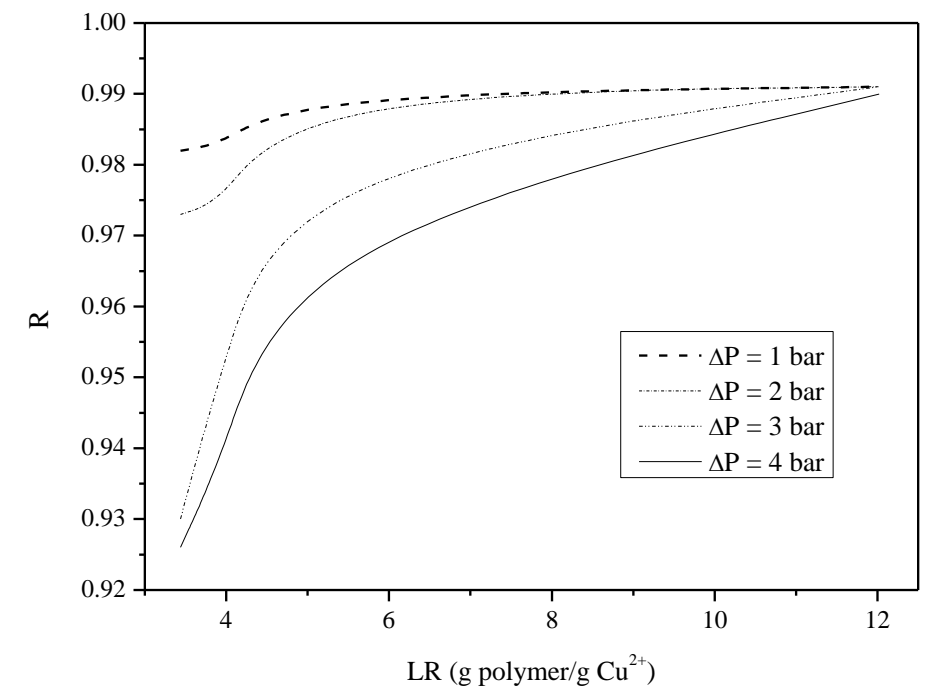

Fig. 2. Change of $\mathrm{Cu}^{2+}$ rejection coefficients with polymer/metal loading ratio and transmembrane pressure. Polymer: Partially Ethoxylated Polyethylenimine (PEIPE). Membrane: Carbosep M5; pH = 6

From this figure, it is possible to obtain the loading ratio for a working

16 transmembrane pressure and a required $\mathrm{Cu}^{2+}$ rejection coefficient. Once this loading 17 ratio is fixed, the required polymer concentration $\left(\mathrm{C}_{\mathrm{pol}}\right)$ can be calculated from a given 18 metal concentration $\left(\mathrm{C}_{\mathrm{Cu}}\right)$ by using Eq. (1). 
$1 \quad \mathrm{C}_{\mathrm{pol}}=\mathrm{LR} \cdot \mathrm{C}_{\mathrm{Cu}}$

This polymer concentration can be used to evaluate the costs of polymer as well

3 as to obtain the ratio between the feed stream (stream 1) and the regenerated polymer

4 stream (stream 9).

Next, the key parameter to be calculated is the membrane area required. This

6 parameter is directly related to both the permeate flux of the selected membranes and

7 the required production of the plant. The variables that most strongly affect permeate

8 flux are transmembrane pressure $(\Delta \mathrm{P})$ and temperature. Moreover, membrane structure

9 (v. g. membrane porosity) plays a key role on the membrane permeate flux.

10 Fig. 3 shows the influence of transmembrane pressure and temperature on 11 permeate fluxes for two different ceramic membranes, one tubular and one multichannel

12 membrane, of different Molecular Weight Cut Off (MWCO) and different porosity.

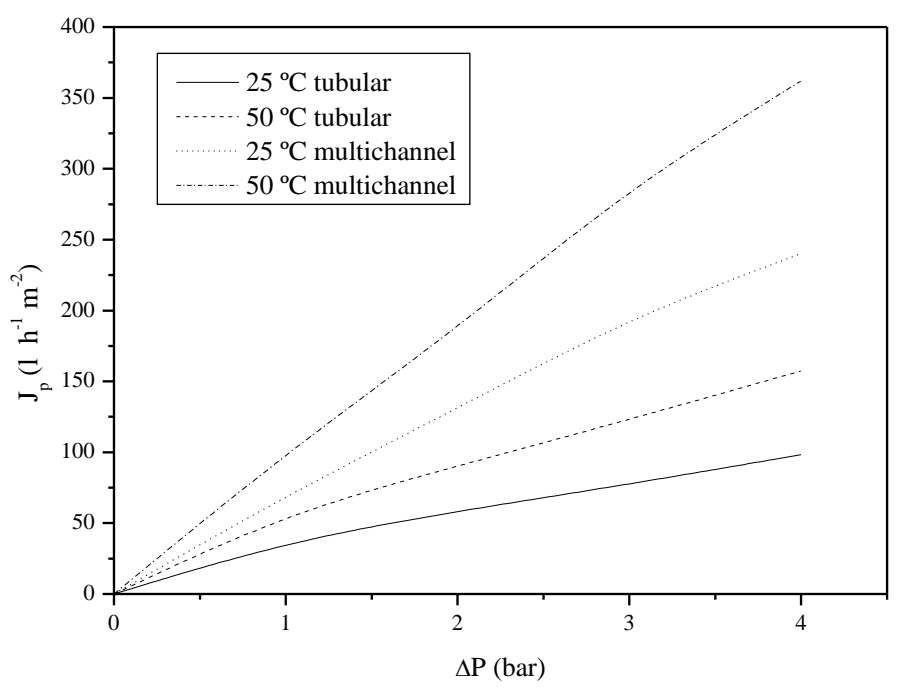

Fig. 3. Cange of permeate flux with temperature and transmembrane pressure for two different membranes: 1) Tubular Carbosep M5, MWCO $=10000$ Da; 2) Multichannel Kerasep, $\mathrm{MWCO}=15000$ $\mathrm{Da} ; \mathrm{pH}=6 ;\left[\mathrm{Cu}^{2+}\right]_{0}=125 \mathrm{ppm}$. [5, 7]. 
2 obtained from a given temperature, transmembrane pressure and membrane type. Once

3 permeate flux is obtained, membrane area can be directly calculated from the required

4 production $\left(\mathrm{Q}_{\mathrm{p}}\right)$ by using Eq. (2).

$5 \quad \mathrm{~A}_{\mathrm{m}}=\frac{\mathrm{Q}_{\mathrm{p}}}{\mathrm{J}_{\mathrm{p}}}$

6 Other important variable is the concentration factor, which is defined as the ratio

7 between the concentration of the retentate from the ultrafiltration module (stream 7) and

8 the feed concentration (stream 3). The value of this factor is directly related to the final

9 polymer concentration, which affects permeate flux. Nevertheless, it will be assumed

10 that the feed stream is diluted enough to consider the influence of polymer

11 concentration on permeate flux negligible compared to the influence of temperature and

12 transmembrane pressure.

13 To finish the design of ultrafiltration section, it is necessary to calculate the 14 pumping power required. This pumping power can be calculated by means of equation

15 (3), where $\mathrm{Q}$ is the volumetric flow pumped $\left(\mathrm{m}^{3} \mathrm{~s}^{-1}\right), \Delta \mathrm{P}$ the pressure (Pa) and $\eta$ the 16 global yield of the pump.

$18 \quad \mathrm{~N}=\frac{\mathrm{Q} \cdot \Delta \mathrm{P}}{\eta}$

Feed pump will work during metal retention step but not during cleaning stages.

21 As regards the pressure supplied by the pump, it will be equal to the selected

22 transmembrane pressure, taking into account both the operating pressure in the module

23 and the pressure drop through the membranes. The pressure that recirculation pump 
1 must overcome will be pressure drop across the module. To calculate the volumetric

2 flow impelled by this pump, it will be necessary to make use of the required tangential

3 velocity and expression (4), which relates volumetric flow (Q) with tangential velocity

$4 \quad$ (v) and cross section (S):

$5 \quad \mathrm{Q}=\mathrm{v} \cdot \mathrm{S}$

6 With respect to the polymer regeneration and metal recovery stage, it aims at 7 recovering the polymer to be further used in the PSU process and to get the metal 8 contained in the waste in its most valuable form. With PSU and electrodeposition 9 techniques it is possible to reuse the selected polymer in several retention cycles [5-7]. 10 Furthermore, this regeneration method not only allows the polymer regeneration, but 11 also it implies very important water savings with respect to other regeneration methods 12 as chemical regeneration [13].

13 In the case of regeneration stage, it will also work in continuous mode and it will 14 be considered that working electrode is made from the same material as the metal ion to 15 be removed (in this case, copper). Moreover, in this stage $\mathrm{Cu}^{2+}$ concentration will be 16 diminished from the concentration in retentate stream of the ultrafiltration section 17 (stream 7) to the concentration of the inlet stream (stream 1).

18 Regarding polymer regeneration stage by electrodeposition, electrode volume 19 can be considered the most important variable for the design of the regeneration system.

20 To calculate this parameter, a mass balance can be carried out around the regeneration 21 stage (Eq. 5) in order to obtain required deposition rate $\left(\mathrm{r}_{\mathrm{d}}, \mathrm{g} \mathrm{h}^{-1}\right)$ to reach the target final $22 \mathrm{Cu}^{2+}$ concentration: 
1 where $\mathrm{Q}^{\mathrm{i}}$ and $\mathrm{C}_{\mathrm{Cu}}^{\mathrm{i}}$ are the volumetric flow rate $\left(\mathrm{h} \mathrm{h}^{-1}\right)$ and $\mathrm{Cu}^{2+}$ concentration $\left(\mathrm{g} \mathrm{l}^{-1}\right)$ in

2 current $i$, respectively. At steady state, flow rates of streams 7 and $9\left(\mathrm{Q}^{7}, \mathrm{Q}^{9}\right)$ should be

3 equal and will be denoted as $\mathrm{Q}_{\mathrm{r}}$ from now on. This flow rate (and polymer concentration

4 in stream 9) will determine the polymer/metal ratio in the ultrafiltration stage.

5 Moreover, the electrodeposition rate can be related to the current density $\left(\mathrm{j}, \mathrm{A} \mathrm{m}^{-}\right.$

$\left.6{ }^{2}\right)$, the electrode area $\left(A_{e}, m^{2}\right)$, and the current efficiency $\left(\eta_{d}\right)$ by using Faraday's law, 7 expression (6):

$8 \quad r_{d}=\frac{j \cdot A_{e} \cdot M \cdot 3600 \cdot \eta_{d}}{F \cdot n}$

9 where $r_{d}$ is the electrodeposition velocity $\left(\mathrm{g} \mathrm{h}^{-1}\right), M$ is the copper atomic weight $(\mathrm{M}=$ $\left.1063.54 \mathrm{~g} \mathrm{~mol}^{-1}\right), \mathrm{F}$ is the Faraday constant $\left(\mathrm{F}=96500 \mathrm{C} \mathrm{mol}^{-1}\right), \mathrm{n}$ the moles of electrons 11 necessary to reduce a mole of $\mathrm{Cu}^{2+}(\mathrm{n}=2)$, and 3600 a factor of units conversion. Combining Eqs. (5) and (6) and using $\Delta \mathrm{C}$ as the decrease on copper

13 concentration through the regeneration stage $\left(\mathrm{g}^{-1}\right)$, Eq. (7) can be obtained:

$14 \quad \theta=\frac{A_{e}}{Q_{r} \cdot \Delta C}=\frac{F \cdot n}{j \cdot M \cdot 3600 \cdot \eta_{d}}$

15 where $\theta$ represents the ratio $\mathrm{A}_{\mathrm{e}} / \mathrm{Q}_{\mathrm{r}} \cdot \Delta \mathrm{C}\left(\mathrm{h} \mathrm{m}^{2} \mathrm{~g}^{-1}\right)$.

Finally, it is important to keep in mind that current efficiency depends on both

17 cell design (mass transfer coefficient) and current density. Fig. 4 gathers the influence

18 of current density on the value of the parameter $\theta$ for different values of the mass

19 transfer coefficient [6]. 


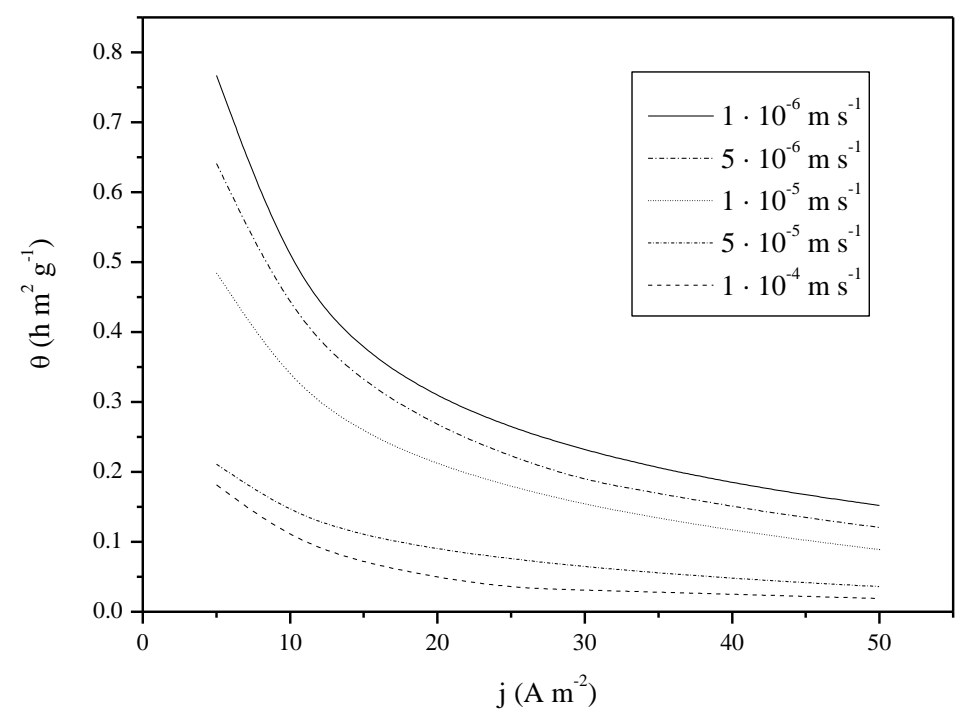

1

$6 \quad \mathrm{~A}_{\mathrm{e}}=\theta \cdot \mathrm{Q}_{\mathrm{r}} \cdot \Delta \mathrm{C}$

8 calculated from Eq. (9):

$9 \quad \mathrm{~W}=\mathrm{V} \cdot \mathrm{I}$

10 being $\mathrm{W}$ the required power $(\mathrm{W}), \mathrm{V}$ the voltage $(\mathrm{V})$ and $\mathrm{I}$ the current intensity (A).

11 Intensity can be obtained by multiplying the selected current density by the calculated 12 electrode area. Finally, voltage can be related with intensity by obtaining an empirical 13 equation that will depend on the selected system.

\section{Costs calculation procedure}

The cost analysis of an industrial process should include both start-up capital

16 and exploitation costs. However, in wastewater treatment processes the immobilized

17 capital is the most important item, being the start-up and the current capital negligible. 
1 To calculate the amortization we have decided to suppose a 10-year linear type, without

2 value for money update.

\subsection{Investment}

Investment of this plant will be calculated on the base of the cost of the two key equipments in the proposed process: membranes and modules for ultrafiltration section, and electrochemical reactor for the polymer regeneration and metal recovery stage. The rest of immobilized capital (piping, instrumentation, valves, etc.) will be calculated as a percentage of this main investment. To calculate the cost of these key equipments, two Williams equations will be obtained. These well-known Williams equations [17] can be defined as empirical expressions that relate the cost of a given equipment, $\mathrm{C}$, with the value of a design parameter, $\alpha$ (power for pumps, volume for tanks, etc.), Eq. (10).

$$
\mathrm{C}=\mathrm{a} \cdot \alpha^{\mathrm{b}}
$$

where $a$ and $b$ are empirical parameters obtained from actual cost data.

The cost of membranes and modules can be directly related with the necessary membrane area. Specifically, it is possible to obtain similar values of permeate flux in two systems with similar membranes even though if they have an area ratio 80:1 [18]. Thus, this equation was used in order to relate the cost of ceramic membranes and modules with the required membrane area. In this work, this equation has been obtained from direct manufacturer budgets (Novasep) and from data obtained in literature for a membrane area of $15 \mathrm{~m}^{2}$ [19].

For the case of the electrochemical reactor, it is possible to obtain data from literature [20-22] and from suppliers budgets (Electrocell, Skjem, Denmark, 2006;

Electrosynthesis Company, Lancaster (NY), USA, 2005), and fit also these data to a Williams equation. 
2 the Spanish industrial cost index obtained from the Spanish official agency of statistics

3 (www.ine.es). Fig. 5 represents the price of membranes and modules as a function of

4 membrane area, and the price of the electrochemical reactor related with the electrode

5 area. In both cases, the best fit of the Williams equation is also represented.

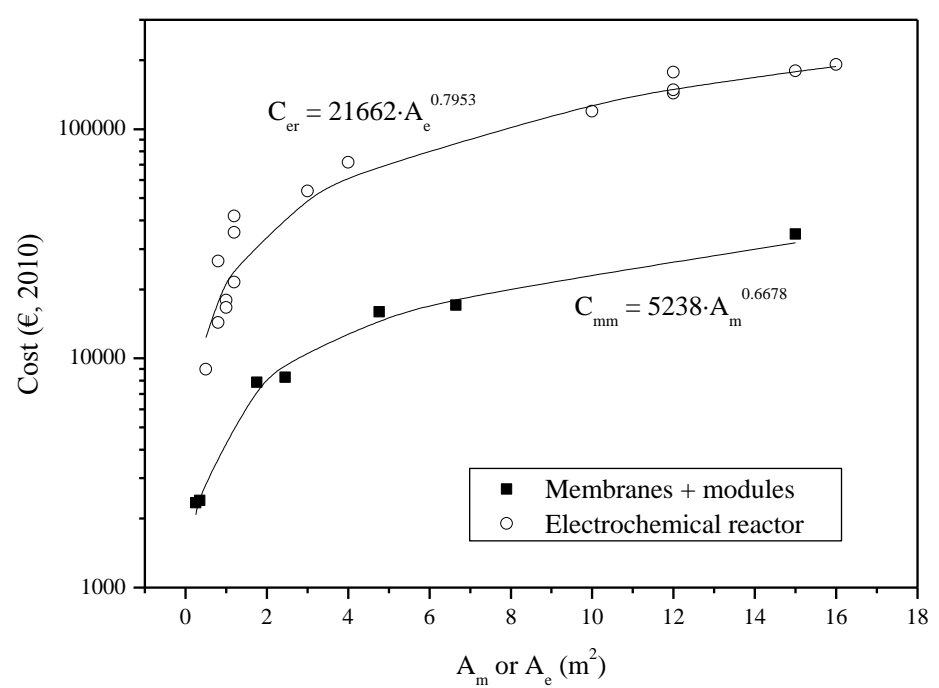

Fig. 5. Cost of the main equipment for ultrafiltration (membrane + modules, $\mathrm{C}_{\mathrm{mm}}$ ) and electrodeposition (electrochemical reactor, $C_{\text {er }}$ ) and fit to Williams equation. Data taken from: 1) Ultrafiltration: [19], budgets from Novasep®; 2) Electrodeposition: [20-22], budgets from: Electrocell, Skjem, Denmark, 2006; Electrosynthesis Company, Lancaster (NY), USA, 2005.

11 Thus, Eqs. (11) and (12) can be applied to obtain the cost of membranes and

12 modules $\left(\mathrm{C}_{\mathrm{mm}}, €, 2010\right)$ related with the membrane area $\left(\mathrm{A}_{\mathrm{m}}, \mathrm{m}^{2}\right)$ and the cost of the

13 electrochemical reactor $\left(C_{e r}, €, 2010\right)$ as a function of the electrode area $\left(A_{m}, m^{2}\right)$

$14 \quad \mathrm{C}_{\mathrm{mm}}(€)=5238 \cdot \mathrm{A}_{\mathrm{m}}^{0.6678}$

In the case of Eq. (11), it should only be used for ceramic membranes and in the range of membranes areas used to carry out the fitting $\left(A_{m}<15 \mathrm{~m}^{2}\right)$. In this range of areas, Williams equation can be applied because it is possible to use higher modules, which work with a bigger number of membranes, in order to increase membrane area. 
1 For much higher membrane areas, it is necessary to use several modules and,

2 consequently, scaling-up in terms of economics tends to be linear, this is to say,

3 exponent of Williams equation tends to 1.

4 To quantify other immobilized costs, the factorial estimation method is used.

5 This method is based on the calculation of the rest of immobilized costs as a fraction of

6 the immobilized costs basis (modules and membranes, and electrochemical reactor).

7 The factors to be used to this calculation depend on the characteristics of the process. In

8 the case of the proposed process, the factors selected are gathered in Table 1 [23].

9

10 Table 1. Factors for the calculation of capital investment from the immobilized costs basis [23].

\begin{tabular}{|c|c|}
\hline Concept & $\begin{array}{l}\text { Factor (fraction of the base } \\
\text { immobilized) }\end{array}$ \\
\hline Equipment and machinery & 1 \\
\hline Equipment installation & 0.47 \\
\hline Instrumentation and controls (installed) & 0.18 \\
\hline Piping (installed) & 0.66 \\
\hline Electrical (installed) & 0.11 \\
\hline Buildings (including services) & 0.18 \\
\hline Yard improvements & 0.1 \\
\hline Service facilities (installed) & 0.1 \\
\hline Total direct plant cost & 2.8 \\
\hline Engineering supervision & 0.33 \\
\hline Construction expenses & 0.41 \\
\hline Total direct and indirect costs & 3.54 \\
\hline Contractors fees & 0.21 \\
\hline Contingency & 0.42 \\
\hline Fixed capital investment & 4.17 \\
\hline
\end{tabular}


Although the values gathered in Table 1 are obtained from literature, some

2 remarks should be given here:

1) The cost of isolation is considered negligible as working temperatures will be always equal or lower to $50^{\circ} \mathrm{C}$.

2) Finally, the cost of service facilities has been considered smaller than usual as the process will be a subsidiary treatment plant of an industrial process. Taking these factors into account, the total immobilized cost of the section (C)

8 can be calculated by using Eq. (13):

$9 \mathrm{C}=4.17 \cdot\left(\mathrm{C}_{\mathrm{mm}}+\mathrm{C}_{\mathrm{er}}\right)$

\subsection{Operation and amortization costs}

11 Once the investment has been calculated, it is necessary to evaluate the operation

12 and amortization costs. With respect to the ultrafiltration section, the most important

13 items to be quantified are those related to pumping energy, membrane replacement, 14 reagents consumption, cleaning, labor and maintenance. operation factor of $8,000 \mathrm{~h} \mathrm{yr}^{-1}$ for the feed pump and $6,000 \mathrm{~h} \mathrm{yr}^{-1}$ for the recircualtion

17 pump will be selected, as the former will only work during retention cycles but the latter

18 will work during both retention and cleaning stages. The cost of the energy will be set to $190.06 €(\mathrm{kWh})^{-1}$.

With respect to membrane replacement, membranes life-time of two years will

21 be considered as ceramic membranes have life-times considerably higher than 22 polymeric ones. To calculate the cost of one membrane replacement, it will be 23 considered a cost of $1000 € \mathrm{~m}^{-2}$, according to the data supplied by the manufacturer 24 Novasep. This value is in the range of values reported in literature, where it is mentioned a cost of membrane replacement for inorganic membranes from 500 to 3000 
$1 € \mathrm{~m}^{-2}$ [19]. As membranes life-time is 2 years, a cost of $500 € \mathrm{~m}^{-2}$ year $^{-1}$ will be

2 considered.

Regarding reagents consumption, a special attention should be paid to polymer.

4 According to the bulk offer from supplier Aldrich, the unit cost for a $37 \%$ wt. polymer

5 solution would be approximately $200 € \mathrm{~kg}^{-1}$. Generally, polymers exhibit high stability

6 after successive working cycles [9]. As a criterion to estimate the quantity of pure

7 polymer used in the process, there will be a complete replacement of polymer in the

8 system after each $8000 \mathrm{~h}$ of work.

To calculate the quantity of polymer present in the system, it will be considered

10 that tanks R-1 and R-2 operate at $50 \%$ of maximum capacity without considering 11 overdimension factor. Polymer concentration in any of these reactors can be obtained 12 from Fig. 2 (to obtain loading ratio) and Eq. (1) for any single metal concentration to be treated. Volume of tank R-1 can be calculated taking into account that it must be able to store the volumetric flow of the feed stream together with the recirculated polymer stream during the cleaning process $(2 \mathrm{~h})$. Tank R-2 is also designed with a residence

16 time of $2 \mathrm{~h}$. It will be considered that the rest of chemical reagents are included in the costs of the cleaning process.

With respect to cleaning, it can represent from $10 \%$ to $30 \%$ of the total operating costs [24]. As the present process is conceived to treat diluted streams, we have considered that cleaning will represent a $10 \%$ of the sum of pumping, membrane 21 replacement and reagents costs.

In the case of regeneration stage, the most important operation costs are related with electricity, electrode replacement, labor and maintenance.

The main energy cost of the plant used during polymer regeneration is due to electrodeposition reaction [25]. This cost can be obtained from the power of the power 
1 supply (Eq. 9), and considering a cost of the electricity equal to $0.06 €(\mathrm{kWh})^{-1}$, as it

2 was the case for ultrafitration section.

3

4

6

As it has been previously commented, a copper sheet can be used as working electrode. As counter electrode, an inert material as graphite can be used. In this scenario, working electrode presents an added-value that has not been taken into account, following a conservative criterion.

Maintenance costs will be considered together with ultrafiltration section. Usually, these costs fluctuate from 2 to $5 \%$ of immobilized capital for this type of installations. In this work, a value of $3 \%$ of the base immobilized is selected.

The chemical reagents costs will be negligible in comparison to polymer and the rest of products used during metal retention stage. Finally, labor costs will not be considered as they will strongly depend on the environment where this treatment process is set in: country, type of industry where this process is applied, etc.

\section{Total cost of treatment}

Table 2 and 3 gather the required membrane and electrode area for different treatment flow-rates and inlet concentrations for two different current densities, 25 and $50 \mathrm{~A} \mathrm{~m}^{-2}$, respectively. Tables 4 and 5 summarize, respectively, the investment and operation costs for these two current densities. In these calculations, the main variables that affect ultrafiltration section have been fixed in typical values: required rejection coefficient of $0.97,3$ bar of transmembrane pressure, 1 bar of pressure drop through the membrane module, a concentration factor of 4 , and $50{ }^{\circ} \mathrm{C}$ of temperature. For electrodeposition section, a mass transfer coefficient of $10^{-4} \mathrm{~m} \mathrm{~s}^{-1}$ has been selected. This value has been selected because, in order to treat diluted heavy metal streams, it is necessary to design reactors that maximize mass transfer [25]. 
1 Table 2. Membrane and electrode area calculation for increasing values of the treatment flow2 rate $\left(Q_{1}, 10-40 \mathrm{~m}^{3}\right.$ day $\left.^{-1}\right)$ and concentration in the inlet stream $\left(\mathrm{C}_{1}, 0.125\right.$ to $\left.0.25 \mathrm{~g} \mathrm{l}^{-1}\right)$ for a 3 current density of $25 \mathrm{~A} \mathrm{~m}^{-2}$.

\begin{tabular}{|c|c|c|c|}
\hline $\mathrm{Q}_{1}\left(\mathrm{~m}^{3}\right.$ day $\left.^{-1}\right)$ & $\mathrm{C}_{1}\left(\mathrm{~g} \mathrm{l}^{-1}\right)$ & $\mathrm{A}_{\mathrm{m}}\left(\mathrm{m}^{2}\right)$ & $\mathrm{A}_{\mathrm{e}}\left(\mathrm{m}^{2}\right)$ \\
\hline \multirow{2}{*}{10} & 0.125 & 1.94 & 1.77 \\
\cline { 2 - 4 } & 0.25 & 1.94 & 3.54 \\
\hline \multirow{2}{*}{20} & 0.125 & 3.87 & 3.54 \\
\cline { 2 - 4 } & 0.25 & 3.87 & 7.08 \\
\hline \multirow{2}{*}{30} & 0.125 & 5.81 & 5.31 \\
\cline { 2 - 4 } & 0.25 & 5.81 & 10.63 \\
\hline \multirow{2}{*}{40} & 0.125 & 7.75 & 7.08 \\
\cline { 2 - 4 } & 0.25 & 7.75 & 14.17 \\
\hline
\end{tabular}

5 Table 3. Membrane and electrode area calculation for increasing values of the treatment flow6 rate $\left(\mathrm{Q}_{1}, 10-40 \mathrm{~m}^{3}\right.$ day $\left.^{-1}\right)$ and concentration of the inlet stream $\left(\mathrm{C}_{1}, 0.125\right.$ to $\left.0.25 \mathrm{~g} \mathrm{l}^{-1}\right)$ for a 7 current density of $50 \mathrm{~A} \mathrm{~m}^{-2}$.

\begin{tabular}{|c|c|c|c|}
\hline $\mathrm{Q}_{1}\left(\mathrm{~m}^{3}\right.$ day $\left.^{-1}\right)$ & $\mathrm{C}_{1}\left(\mathrm{~g} \mathrm{l}^{-1}\right)$ & $\mathrm{A}_{\mathrm{m}}\left(\mathrm{m}^{2}\right)$ & $\mathrm{A}_{\mathrm{e}}\left(\mathrm{m}^{2}\right)$ \\
\hline \multirow{2}{*}{10} & 0.125 & 1.94 & 0.99 \\
\cline { 2 - 4 } & 0.25 & 1.94 & 1.98 \\
\hline \multirow{2}{*}{20} & 0.125 & 3.87 & 1.98 \\
\cline { 2 - 4 } & 0.25 & 3.87 & 3.96 \\
\hline \multirow{2}{*}{30} & 0.125 & 5.81 & 2.97 \\
\cline { 2 - 4 } & 0.25 & 5.81 & 5.94 \\
\hline \multirow{2}{*}{40} & 0.125 & 7.75 & 3.96 \\
\cline { 2 - 4 } & 0.25 & 7.75 & 7.92 \\
\hline
\end{tabular}

8

9 Table 4. Investment $(€, 2010)$ and operation $\left(€ \mathrm{~m}^{-3}, 2010\right)$ costs for increasing values of the 10 treatment flow-rate $\left(\mathrm{Q}_{1}, 10-40 \mathrm{~m}^{3} \mathrm{day}^{-1}\right)$ and concentration of the inlet stream $\left(\mathrm{C}_{1}, 0.125\right.$ to 0.25 $11 \mathrm{~g} \mathrm{l}^{-1}$ ) for a current density of $25 \mathrm{~A} \mathrm{~m}^{-2}$.

12

\begin{tabular}{|c|c|c|c|c|c|c|c|c|}
\hline $\mathrm{Q}_{1}\left(\mathrm{~m}^{3} \mathrm{day}^{-1}\right)$ & $\mathrm{C}_{1}\left(\mathrm{~g}^{-1}\right)$ & $\mathrm{C}(€)$ & $\begin{array}{c}\mathrm{C}_{\mathrm{mm}} \\
(\%)\end{array}$ & $\begin{array}{c}\mathrm{C}_{\mathrm{er}} \\
(\%)\end{array}$ & $\begin{array}{c}\text { Total } \\
\left(€ \mathrm{~m}^{-3}\right)\end{array}$ & $\begin{array}{c}\text { Energy } \\
(\%)\end{array}$ & $\begin{array}{c}\text { Amortiz. } \\
(\%)\end{array}$ & $\begin{array}{c}\text { Rest* } \\
(\%)\end{array}$ \\
\hline \multirow{2}{*}{10} & 0.125 & 176261 & 19 & 81 & 6.36 & 5 & 83 & 12 \\
\cline { 2 - 9 } & 0.25 & 280915 & 12 & 88 & 9.83 & 3 & 86 & 11 \\
\hline \multirow{2}{*}{20} & 0.125 & 300905 & 18 & 82 & 5.53 & 5 & 82 & 13 \\
\cline { 2 - 9 } & 0.25 & 482526 & 11 & 89 & 8.56 & 4 & 85 & 11 \\
\hline \multirow{2}{*}{30} & 0.125 & 411656 & 17 & 83 & 5.11 & 6 & 81 & 14 \\
\cline { 2 - 9 } & 0.25 & 662389 & 11 & 89 & 7.90 & 4 & 84 & 12 \\
\hline \multirow{2}{*}{40} & 0.125 & 514283 & 17 & 83 & 4.83 & 6 & 80 & 14 \\
\cline { 2 - 8 } & 0.25 & 829475 & 10 & 90 & 7.47 & 5 & 83 & 12 \\
\hline
\end{tabular}

$13 *$ Membrane replacement, chemicals, cleaning and maintenance. 
1 Table 5. Investment $(€, 2010)$ and operation $\left(€ \mathrm{~m}^{-3}, 2010\right)$ costs for increasing values of the 2 treatment flow-rate $\left(\mathrm{Q}_{1}, 10-40 \mathrm{~m}^{3}\right.$ day $\left.^{-1}\right)$ and concentration of the inlet stream $\left(\mathrm{C}_{1}, 0.125\right.$ to 0.25 $3 \mathrm{~g} \mathrm{l}^{-1}$ ) for a current density of $50 \mathrm{~A} \mathrm{~m}^{-2}$.

\begin{tabular}{|c|c|c|c|c|c|c|c|c|}
\hline $\mathrm{Q}_{1}\left(\mathrm{~m}^{3}\right.$ day $\left.^{-1}\right)$ & $\mathrm{C}_{1}\left(\mathrm{~g}^{-1}\right)$ & $\mathrm{C}(€)$ & $\begin{array}{c}\mathrm{C}_{\mathrm{mm}} \\
(\%)\end{array}$ & $\begin{array}{c}\mathrm{C}_{\mathrm{er}} \\
(\%)\end{array}$ & $\begin{array}{c}\text { Total } \\
\left(€ \mathrm{~m}^{-3}\right)\end{array}$ & $\begin{array}{c}\text { Energy } \\
(\%)\end{array}$ & $\begin{array}{c}\text { Amortiz. } \\
(\%)\end{array}$ & $\begin{array}{c}\text { Rest* } \\
(\%)\end{array}$ \\
\hline \multirow{2}{*}{10} & 0.125 & 123541 & 27 & 73 & 4.67 & 6 & 79 & 14 \\
\cline { 2 - 9 } & 0.25 & 189422 & 18 & 82 & 6.90 & 5 & 82 & 13 \\
\hline \multirow{2}{*}{20} & 0.125 & 209412 & 26 & 74 & 4.07 & 7 & 77 & 15 \\
\cline { 2 - 9 } & 0.25 & 323746 & 17 & 83 & 6.02 & 6 & 81 & 14 \\
\hline \multirow{2}{*}{30} & 0.125 & 285347 & 25 & 75 & 3.76 & 8 & 76 & 16 \\
\cline { 2 - 9 } & 0.25 & 443188 & 16 & 84 & 5.57 & 6 & 80 & 14 \\
\hline \multirow{2}{*}{40} & 0.125 & 355503 & 24 & 76 & 3.56 & 8 & 75 & 17 \\
\cline { 2 - 9 } & 0.25 & 553922 & 15 & 85 & 5.27 & 7 & 79 & 14 \\
\hline
\end{tabular}

$4 *$ Membrane replacement, chemicals, cleaning and maintenance.

As it can be observed, the biggest immobilized cost corresponds to the section of

7 polymer regeneration and metal recovery by electrodeposition. With respect to

8 operation and amortization costs, amortization is the most important one, with a relative

9 cost of around $80 \%$ in all cases.

As expected, treatment cost per unit of volume decreases with increasing flow

11 rates of the target stream and increases with increasing inlet $\mathrm{Cu}^{2+}$ concentration. With

12 respect to current density (the only working variable that has not been fixed in this

13 example), it has a positive effect on treatment costs as electrode requirements decrease

14 with increasing current densities.

On the other hand, it must be mentioned that the treatment of this type of

16 effluents by an authorized managing company, excluding transport costs, reaches 50-60

$17 € \mathrm{Tm}^{-1}$. This price turns the proposed technique in this research into an economically

18 viable alternative to carry out the treatment of the proposed effluent. Moreover, it is

19 important to highlight that the value of the recovered copper can represent an important

20 reduction on the treatment cost. According to the London Metal Exchange (the world's

21 premier non-ferrous metals market), the price of copper is around $9000 \$ \mathrm{Tm}^{-1}$ and its 
1 price has increased by a factor of 3 within the last two years. As an example, for a

2 treatment flow-rate of $20 \mathrm{~m}^{3} \mathrm{day}^{-1}$ and an inlet concentration of $0.25 \mathrm{mg} \mathrm{l}^{-1}$, the total

3 mass of copper recovered per year is $1667 \mathrm{~kg}$, which means an economical return of

4 around $11280 €$ year $^{-1}$. For a current density of $25 \mathrm{~A} \mathrm{~m}^{-2}$, this economical return implies

5 a reduction in treatment costs from $8.56 € \mathrm{~m}^{-3}$ to $6.87 € \mathrm{~m}^{-3}$, this is to say, close to a

$620 \%$ decrease in this costs of treatment. Even in a less favourable scenario (inlet

7 concentration of $0.125 \mathrm{mg} \mathrm{l}^{-1}$ and a price of copper $30 \%$ lower), the sell of the

8 recovered copper would represent a reduction of $14 \%$ on the treatment costs (from 5.33

9 to $€ \mathrm{~m}^{-3}$ to $4.74 € \mathrm{~m}^{-3}$ ) for the same current density.

10 Consequently, the present study confirms that this regeneration method implies

11 important economic savings during treatment. This economical feasibility is joined to

12 the technical and environmental viability of the electrochemical process of polymer

13 regeneration, which was demonstrated in previous works.

\section{5. Conclusions}

This work presents a guide to the calculation of the costs related with a treatment process that involves two stages: a previous membrane process and a subsequent

17 electrodeposition stage. This treatment process should be used to concentrate and

18 recover diluted streams with heavy metal ions.

Throughout this work, it is possible to obtain the most important design

20 parameters (membrane and electrode area) from any given feed flow-rate and inlet

21 copper concentration, once working variables as transmembrane pressure, temperature

22 and current density have been selected. Moreover, Williams equations that relate the

23 cost of the main investment with these design parameters have also been successfully 24 obtained. 
Finally, the calculation of investment and operation costs for typical working

2 conditions was also carried out. It was observed that increasing current density has a

3 positive effect on reducing the final treatment costs. Moreover, it can be concluded that

4 electrodeposition not only is an economically feasible alternative to carry out the

5 polymer regeneration stage, but also it allows recovering the metal ion in its most

6 valuable form, which can significantly reduce the treatment cost.

7

8 References

9 [1] Al-Sahali M, Ettouney HM (2007) Desalination 214:227

10 [2] Kobya M, Bayramoglu M, Eyvaz M (2007) J Hazard Mater 148:311

11 [3] Macedonio F, Curcio E, Drioli E (2007) Desalination 203:396

12 [4] Eslamimanesh A, Hatamipour, MS (2010) Desalination 250:203

13 [5] Llanos J, Pérez Á, Cañizares P (2008) J Membrane Sci 323:28

14 [6] Llanos J, Pérez Á, Rodrigo MA et al (2009) J Hazard Mater 168:25.

15 [7] Llanos J, Pérez Á, Cañizares P (2009) J Membrane Sci 341:37.

16 [8] Geckeler KE, Lange G, Eberhardt H et al. (1980) Pure Appl Chem 52:1883

17 [9] Geckeler KE, Volchek K (1996) Environ Sci Technol 30:725

18 [10] Strathmann H (1980) Sep Sci Technol 15:1135

19 [11] Cañizares P, Pérez Á, Camarillo R (2002) Desalination 144:279

20 [12] Camarillo R, Llanos J, García-Fernández L et al (2010) Sep Purif Technol 70:320

21 [13] Cañizares P, Pérez Á, Llanos J et al (2008) Desalination 223:229

22 [14] Juang R-S, Chiou C-H (2000) J Membrane Sci 177:207 
1 [15] Barron-Zambrano J, Laborie S, Viers Ph et al (2004) J Membrane Sci 229:179

2 [16] Cañizares P, de Lucas A, Pérez Á et al (2005) J Membrane Sci 253:149

3 [17] Perry RH, Green DW, Malone YJO (2001). Manual del Ingeniero Químico.

4 McGraw-Hill, Madrid.

5 [18] Ball P (2000) Membrane Technol 117:10

6 [19] Cheryan M (1998) Ultrafiltration and Microfiltration Handbook. Technomic,

$7 \quad$ Lancaster $(\mathrm{PA})$

8 [20] Electrochemistry Encyclopedia: < http://electrochem.cwru.edu/encycl/>. Accessed 9 Dec, $15^{\text {th }} 2010$.

10 [21] Cañizares P, Paz R, Sáez C. et al. (2009) J Environ Manage 90:410

11 [22] Barton GW, Scott AC (1992) J Appl Electrochem 22:687

12 [23] Awad YM, Abuzaid NS (1997) J Environ Sci Heal A 32:1393

13 [24] Eykamp W (1995) In: Noble RD, Stern SA (eds) Membrane Separation

14 Technology: Principles and applications. Elsevier Science, Amsterdam.

15 [25] Jüttner K, Galla U, Schmieder H (2000) Electrochim Acta 45:2575

16

17 